\title{
METODOLOGIA DE CUSTEIO PARA A ERGONOMIA
}

\author{
ERGONOMICS-BASED COSTING METHODOLOGY
}

\author{
JOSÉ ROBERTO DOURADO MAFRA \\ Professor Adjunto do Departamento de Contabilidade \\ da Faculdade de Administração e Ciências Contábeis \\ da Universidade Federal do Rio de Janeiro - RJ \\ E-mail:mafra@facc.ufrj.br
}

\section{RESUMO}

Uma metodologia de Custeio para Ergonomia é apresentada neste artigo.Aqui o custeio é construído em paralelo ao processo da Análise de Ergonomia. Faz-se uma breve revisão da literatura. Essa metodologia de custeio abrange uma estimativa inicial de custos e a posterior aferição desses custos, decorrentes da ausência de Ergonomia no delineamento das situações em estudo; num outro momento, são feitos os cálculos dos custos das correções, ou investimentos necessários e a avaliação dos benefícios aportados pela nova concepção. A aplicação dessa metodologia é exemplificada em um estudo de caso de uma cozinha industrial, onde foi realizada uma Análise Ergonômica do Trabalho. No estudo de caso, a ausência de ergonomia é caracterizada por indicadores econômicos de efetividade na empresa. Conclui-se que essa metodologia de custeio mostra como problemas no desempenho impactam no nุegócio, economicamente, caracterizados em saúde, qualidade de vida e produtividade no trabalho. Nesse sentido, acredita-se ter contribuído com o estado da prática, contabilizando os custos e avaliando a viabilidade da solução.

Palavras-chave: Custeio; Análise Ergonômica do Trabalho; Custo Sombra; Custo Benefício.

\section{ABSTRACT}

This paper discusses an ergonomics-based costing methodology, in which the costing process and the ergonomic work analysis are realized at the same time. A briefbibliographic review is presented. Two questions are pointed out regarding the economic evaluation of ergonomic interventions: one is the costing problem and the other evaluation itself. This costing methodology involves an initial costing estimate of the lack of ergonomics in the study case, followed by the checking of data validity; then, the costs of solutions are calculated and the benefits of the new conception are assessed. The methodology is applied to one example, i.e. a case study of an industrial kitchen, where an ergonomic work analysis was performed. In the studied case, the lack of ergonomics is characterized by economic indicators of company efficacy. This costing methodology shows how performance problems affect the business in economic terms, characterized in health, quality of life and productivity at work. In this sense, we believe this methodology has contributed to practice by accounting for and evaluating costs and assessing the viability of solutions.

Keywords: Costing; Ergonomic Work Analysis; Șhadow Cost; Cost Benefit. 


\section{INTRODUÇÃO}

Segundo mencionou ludícibus (1995), "tem sido inegável o sucesso, na esfera gerencial, dos conceitos e técnicas de gestão estratégica de custos". Nesse contexto a Contabilidade "forçosamente" precisa dar atenção aos "avanços ocorridos nas empresas na área de qualidade total, na busca pela competitividade e maior eficácia nos negócios". Apesar de alguma resistência quanto aos novos conceitos, técnicas e métodos, como os do Life-Cycle Costing, Target Costing, Activity Based Costing, entre outros, sob as premissas mais variadas, as empresas de ponta vêm adotando tais procedimentos porque "melhoram a qualidade dos indicadores contábeis, dando condições para diminuir custos desnecessários (que não agregam valor), aumentando os lucros" (op.cit., 1995).

Hoje a Qualidade já faz parte do dia-a-dia das organizações. Sob o símbolo da Qualidade, como uma palavrachave, abriga-se uma série de ferramentas gerenciais, em que "uma das áreas importantes é a de Custos da Qualidade". Já foi demonstrado que melhoria de qualidade reduz custos, em todas as fases do ciclo de desenvolvimento de um produto, principalmente na fase de projeto, com "métodos de planejamento estatístico de experimentos, em particular o método de Taguchi”; em que os componentes básicos do custo são: matéria-prima, energia, mão-deobra, despesas provenientes de produção de itens defeituosos, recursos utilizados em itens defeituosos, resíduos resultantes da produção, etc. Reduzindo custos "através de práticas gerências adequadas e tecnologias eficientes" (PETENATE, 1995).

A Ergonomia, aliada ao movimento da qualidade, coloca-se como uma base para a proposta de melhoria contínua dos processos produtivos. Porém, diferentemente da qualidade, que é uma exigência de mercado (Normas ISO), a Ergonomia tem, no Brasil, exigência de lei, pela Norma Regulamentadora 17, do Ministério do Trabalho e Emprego. Compreende-se sua exigência legal pelo simples fato de as condições de trabalho colocarem em risco a integridade física e mental dos trabalhadores. Mas, curiosamente, em geral, as melhorias da Ergonomia trazem, efetivamente, benefícios para os processos produtivos. Isso ocorre em termos de melhorias em diversos aspectos do processo, tais como: produtividade, qualidade da produção, redução de erros, moral dos trabalhadores, entre outros, e que, em todos os casos, podem ser traduzidos em resultados financeiros.

É importante ressaltar que, em um processo produtivo, ocorrem perdas, como falhas na gestão de saúde, do meio ambiente, da segurança ocupacional. Além de perdas patrimoniais, de eficiência e de produtividade, que nem sempre ficam evidentes nos relatórios gerenciais. Nesse sentido, a metodologia da Ergonomia torna as falhas e suas respectivas perdas evidentes. Foi incorporado, nesta proposta, um conceito proveniente da economia: o valor, que se define como forma de aferição de utilidade e custos.

Cabe mencionar que, para o nosso entendimento, custos ergonômicos são resultados da ausência de Ergonomia. Dessa forma, as perdas no processo, diretas ou relativas a problemas com Ergonomia, são, então, classificadas como "custos ergonômicos". Nessa aferição, são evidenciados os shadow costs. Para a aplicação da metodologia da Ergonomia, torna-se necessária uma abordagem participativa e social do trabalho.

Neste artigo, apresenta-se uma metodologia de Custeio para Ergonomia (MAFRA, 2004), na qual o custeio é construído simultaneamente ao processo da análise das atividades de trabalho. Essa abordagem consiste numa visão orientada da organização do trabalho e da produção, que se utiliza da abordagem participativa e contextualizada da Ergonomia. Essa metodologia abrange uma Estimativa Inicial e a aferição dos custos da ausência da Ergonomia, o cálculo dos custos da correção e a avaliação das vantagens econômicas da nova concepção.

O caso, em que foi aplicada essa metodologia foi extraído de um estudo de caso de uma cozinha industrial (MAFRA e SILVA, 2001). A situação estudada foi modelada pela Análise Ergonômica do Trabalho (AET). Para este artigo foram ressaltadas apenas as características relevantes para caracterizar a metodologia de custeio e as possibilidades de informações para a tomada de decisões de investimentos. Nesse sentido, um estudo de caso tenta esclarecer uma decisão ou um conjunto de decisões: o motivo pelo qual foram tomadas, como foram implementadas e com quais resultados. Schramm (apud YIN, 2001).

\section{CONTEXTO REFERENCIAL}

Diante da definição de ergonomia, divulgada no IEA/ HFES 2000, e do problema colocado por ergonomistas, tais como: Hendrick (1997), Alexander (1995), Oxenburgh (1997) e Budnick (1998), de a ergonomia não ser procurada pelas empresas e organizações, apesar de oferecer benefícios reais ao negócio, ainda ser atual, a questão que se coloca: como avaliar se uma intervenção de Ergonomia é viável (e em quanto) economicamente? Para entender as questões do diálogo entre ergonomistas e homens de negócios, ao via- bilizarem projetos e programas de ergonomia na empresa, $e$ a forma como vem sendo encaminhado o problema da avaliação econômica da Ergonomia, buscou-se, na literatura, o estado do conhecimento a respeito desse tema.

Como é demonstrado na literatura, variam, consideravelmente, os caminhos para demonstrar as vantagens econômicas da Ergonomia. Essas demonstrações vão desde o desenvolvimento de um modelo de caso de negócio, umas mais elaboradas, outras qualitativas, até abordagens 
de planilhas. De qualquer forma, todas as contribuições ajudam a confirmar que as intervenções de Ergonomia oferecem benefícios consideráveis para a organização em questão, incluindo resultados financeiros quantificáveis.

Num editorial da Applied Ergonomics, tratando da efetividade de custos da ergonomia, Stanton e Baber (2003), mencionam que um dos estudos clássicos de efetividade de custos da Ergonomia, ocorrido na década de 70, veio do dispositivo de luz de freio colocada no centro e no alto do vidro traseiro nos automóveis (McKNIGHT e SHINAR, 1992; AKERBOOM et al., 1993). Esse tipo de colocação da luz de freio oferece vantagens cognitivas sobre as luzes de freio convencionais. Estudos posteriores mostraram que os custos eram pequenos (US\$ 10 por carro) e os benefícios bem maiores (estimados em torno US\$900 milhões de economias anuais), do que tinham sido antecipados. Os autores lamentam que nem todas as intervenções sejam de justificativas tão claras.

Beevis e Slade (1970) argumentam que justificativas para melhorias no desempenho de sistemas que envolvem seres humanos e máquinas, apesar de necessárias, não são suficientes sem o apoio de uma análise de custo-benefício. Apontam uma contradição no modo como essa evidência não estava coberta. Para descobrir se as intervenções de ergonomia eram efetivas em custos, eram feitas medidas antes e depois da intervenção, após isso ganhos (ou perdas) eram contabilizados. Essa é uma posição insatisfatória para qualquer organização diante da implementação de mudanças. Homens de negócios precisam de que os custos e ganhos sejam identificados antes da decisão de implementar as mudanças a serem feitas. Um sinal de maturidade da disciplina é quanto se pode antecipar na identificação de expectativas de retornos (perdas e ganhos).

$\mathrm{Na}$ década de noventa, Kragt (1992) escreveu um livro sobre Melhorias no Desempenho Industrial, descrevendo alguns estudos com o potencial de benefícios financeiros provenientes das intervenções ergonômicas. O interessante é que se apresentam variações em como os custos e benefícios foram contabilizados.

Hendrick (1997) enfatiza que as organizações, usualmente, não estão aptas para justificar a intervenção a não ser que exista um claro benefício econômico para isso. Para auxiliar nessa abordagem, Hendrick delineia como identificar, claramente, custos e benefícios, ao desenvolver uma proposta de intervenção ergonômica para uma empresa.

Nesse sentido, Hendrick (2003) argumenta que o ergonomista profissional precisa colocar suas propostas ergonômicas em termos econômicos, ou seja, é necessário falar na mesma linguagem, já que as decisões a respeito de mudanças devem ser racionalizadas em bases financeiras. Essa proposta delineada por Hendrick serve de base de argumentação para qualquer intervenção ergonômica. Sua boa notícia é que, normalmente, bons projetos de Ergonomia têm resultados com expressivos benefícios econômicos, com casos que apóiam essa afirmativa.

Oxenburgh (1997) propôs um sistema de análise de custo-benefício, baseado no trabalho de Liukkonen, que incorpora alguns dos conceitos de Custeio Baseado na
Atividade ( $A B C$ - Activity Based Costing). O ABC foi um aprimoramento da contabilidade gerencial para melhorar a informação contábil para os gerentes e administradores das empresas. Nesse sistema de custeio baseado na atividade ou $A B C$, assume-se como pressuposto que os recursos de uma empresa são consumidos por suas atividades e não por produtos ou serviços que ela fabrica (NESS e CUCUZZA, 1995).

Oxenburgh (2004), com base em seu método, desenvolveu um programa de computador. Seu método de análise baseia-se nos custos diretos e indiretos do trabalho, e os custos anteriores às mudanças são comparados com o previsto, no caso de planejamento e decisão, ou após a intervenção, e mais o custo das mudanças.

Um modelo de caso de negócio é proposto por Seeley e Marklin (2003), assinalando que administradores corporativos podem, nem sempre, entender a relação entre uma intervenção ergonômica e os benefícios financeiros para a companhia. Eles também argumentam que a Ergonomia tem que aprender a linguagem do negócio para colocar seu trabalho de uma maneira mais efetiva.

Kirwan (2003), em um estudo de caso de ergonomia na área nuclear, descreve métodos que oferecem uma análise qualitativa de custo-benefício de diferentes setores. Apesar de não ser apresentada nenhuma análise formal das economias da ergonomia, Kirwan argumenta que os custos de não investir na ergonomia numa indústria crítica em segurança está além da compreensão. Nesse caso, é claro, como os acidentes prévios podem atestar, não existe muita pressão para um caso de negócio formal.

Sen e Yeow (2003) conduziram um estudo para verificar se as intervenções ergonômicas podem provar sua viabilidade econômica em países em desenvolvimento. No caso apresentado, o mapeamento revelou que a causa de muitos dos problemas encontrados estavam num design inicial pobre. As melhorias pouparam mais de US $\$ 500.000$ no primeiro ano e os custos menos de $2 \%$, tornando essa uma proposta extremamente rentável para a organização.

MacLeod (2003) propõe uma aglomeração de resultados de diversos métodos de ergonomia, numa idéia de triangulação de dados qualitativos e quantitativos, partindo de uma posição anterior à intervenção, para uma posição desejada. Essa triangulação de dados de uma variedade de fontes é um meio de reduzir o erro e aumentar a precisão ao estabelecer o problema e a proposta de intervenção. MacLeod argumenta sobre a dificuldade de estimar os benefícios financeiros das intervenções de ergonomia. Faz considerações em torno de questões amplas da efetividade da ergonomia e, em particular, menciona que é a ergonomia e não a tecnologia por si, que irá permitir os benefícios esperados. Para isso, Macleod desenvolve o conceito de fitness-for-purpose, em que a utilidade de um sistema é o grau no qual esse atinge os objetivos de usabilidade, confiabilidade e desempenho.

MacLeod não apresenta uma planilha financeira para a ergonomia, argumentando que os custos das intervenções ergonômicas são normalmente insignificantes quando comparados com os custos totais das operações. 
Stanton e Young (2003) apresentam um método para análise da utilidade das intervenções ergonômicas. A abordagem usa dados financeiros com valores de confiabilidade e validação, para determinar a efetividade do custo de aplicação em treinamento dos métodos ergonômicos em projeto de produto. Eles estão em um estágio inicial de desenvolvimento de sua fórmula e tratamento dos dados, mas apontam um caminho para uma abordagem mais formal da efetividade de custos. Stanton e Young alertam que, mesmo na presente forma, tanto os valores relativos quanto os absolutos devem ter uma abordagem de maior credibilidade.

Beevis (2003) reedita seu artigo de 1970, atualizando as questões, e aponta dificuldades na identificação dos benefícios que podem ocorrer em virtude de alguns desses benefícios serem invisíveis. Ele sugere que quando nas organizações os administradores estão indiferentes ao problema, pode ser preciso um modelo de "caso de negócio" que preveja a viabilidade econômica da proposta de intervenção, para convencê-los da necessidade de investir. O que é diferente de a organização "arriscar no escuro" com os custos da intervenção, para, após o fato, provar que a intervenção ergonômica foi viável.

Beevis identifica três categorias principais para a informação financeira: custos poupados (incluindo correta identificação do problema raiz ao invés de gastar dinheiro corrigindo o problema errado, aumento da produtividade, redução de danos, melhoria no moral, aumento de competência, entre outras), custo evitado (incluindo perda de vendas, aumento do treinamento, melhoria de suporte e manutenção, melhoria nas taxas de rejeição) e novas oportunidades (incluindo projeto de sistemas flexíveis, expansão de mercados para negócios e maior âmbito de usuários). Ele conclui que comparado com as poupanças, o custo de uma intervenção ergonômica é, geralmente, bastante favorável.

Como se pode notar, existem contribuições importantes e os ergonomistas possuem uma base de conhecimento útil para construir um caso de negócios para as intervenções de ergonomia. Os casos vistos sugerem que os custos do envolvimento e da intervenção ergonômica tendem a ser uma pequena fração do orçamento total. Os custos das intervenções figuram em torno de $1 \%$ a $12 \%$ (HENDRICK, 2003), em que se situam com payback periods de 6 a 18 meses (OXENBURGH, 2004). O que representa um quadro bem otimista para a Ergonomia.

Do ponto de vista da Ergonomia, Hendrick (2003) avalia o projeto por uma base delineada de custos e benefícios da intervenção, com uma abordagem de macroergonomia, que é a base para a montagem de um caso de negócios que pode fazer previsões, como sugerido por Beeves (2003). $\mathrm{E}$, num primeiro momento, foi seguida essa mesma linha (MAFRA e VIDAL, 2002), com alguns desdobramentos menos tangíveis. Mas, listar custos e benefícios não é uma aplicação genérica e a identificação, caso a caso, é uma tarefa que precisa ser metodizada.

Assim, quando se trata de projetos ou programas de Ergonomia, em virtude de suas características particulares e intangíveis, para os gestores das empresas a contabili- dade tradicional oculta muitos desses elementos e a contabilidade estratégica não contempla todos os elementos, pois estão nos níveis táticos e operacionais. Já o Custeio Baseado em Atividades, dependendo da profundidade e adaptação da aplicação do método, evidencia-os melhor, como pôde ser demonstrado por Oxenburgh.

No caso do método para análise da utilidade, de Stanton e Young (2003), para determinar a efetividade do custo, verifica-se que é uma abordagem interessante. Porém, além de estarem em um estágio inicial de desenvolvimento de sua fórmula e tratamento dos dados, é um modelo parcial e foi aplicado na avaliação da assimilação de treinamento em Ergonomia. Mas, como mencionado anteriormente, aponta um caminho para uma abordagem mais formal da efetividade de custos.

Nos parágrafos precedentes, viu-se a importância da economia na ergonomia e de tentativas de se fazerem as apropriações de custos e benefícios, em diversas modalidades, desde considerações macroeconômicas, passando por uma variante da abordagem $A B C$, até um modelo de utilidade. Stanton e Baber (2003) concluem que, como uma disciplina, a Ergonomia tem ainda que determinar a melhor maneira, ou seja, um método de apresentar essa informação fundamental, de custo da intervenção e benefícios financeiros obtidos da implementação.

O que se observa das propostas levantadas acima é a falta de um modelo estruturado de valor da ergonomia. Por outro lado, o fato de a origem de dados para os indicadores econômicos estar na raiz dos problemas, é o que nos permitiu a construção de uma estrutura centrada na análise da realidade de trabalho, o Modelo Operante. O Modelo Operante é uma representação da forma como o problema acontece na situação real de trabalho, muitas vezes diferente do que foi previsto acontecer segundo os procedimentos de trabalho, ou seja, quando se trata do trabalho humano e da organização, o que a Análise da Ergonomia produz na fase de análise sistemática é a identificação e evidenciação da raiz do problema, em sua relação de causa e feito. Os problemas que se manifestam enquanto prejuízos para a saúde e a produtividade, na maioria das vezes se inserem nessa diferença entre trabalho real e trabalho prescrito.

Duas questões devem ser ressaltadas, em termos da avaliação das intervenções ergonômicas, que dizem respeito às avaliações econômicas. Em primeiro, a questão do custeio e, em segundo, a avaliação propriamente dita. Ou seja, o problema comum ao se estruturar uma análise financeira de projetos de investimento persiste. Segundo especialistas, o grande problema da análise de investimentos está na determinação dos elementos relevantes que irão compor a formulação da análise.

Com esses elementos, o problema que está sendo estruturado passa a ser uma aplicação de ferramentas matemáticas, bem como a sensibilidade do analista, para a avaliação. Nesse sentido, a forma de contabilizar as receitas e as despesas, que compõem o projeto, deve ser aprofunda$\mathrm{da}$, para se entender o problema que se quer analisar. 


\section{CUSTEIO BASEADO NA ANÁLISE DE ERGONOMIA}

Como se mencionou, anteriormente, esse procedimento de custeio está acoplado ao procedimento metodológico da Análise de Ergonomia. É o mesmo que dizer que na seqüência de etapas da Análise Ergonômica dentro de uma empresa, serão associados procedimentos de custeio, de onde serão derivados os elementos da avaliação econômica da intervenção em questão. Por Análise de Ergonomia, está-se referindo a uma metodologia que aborda o processo de produção como uma rede, formada de sistemas técnicos, organizacionais e de pessoas.

Nesse sentido, a visão da análise econômica para um empreendimento, num primeiro momento, parte de uma visão mais ampla da conjuntura e da posição relativa da empresa, dentro desse contexto, ou seja, traça-se o histórico e a caracterização da empresa no estado anterior dentro de um cenário mais amplo. Num segundo momento, passa-se a avaliar as condições internas de operacionalidade, apontando-se uma Estimativa Inicial, de Custo Ergonômico, seguida pela identificação de problemas, com as perspectivas de custo, que culmina com o mapeamento dos problemas identificados naquela situação, para se montar o Quadro de Custos Ergonômicos da empresa.

Com base nesse quadro, determinam-se os focos de custos e pode-se montar um Quadro de Custos, que são os indicadores de perdas ergonômicas na empresa. Com base nesse quadro e seus focos, podem-se prever os possíveis ganhos (expectativas de retornos dos projetos) e fazer uma avaliação inicial de custo-benefício. Após as análises sistemáticas nos focos, poder-se-á aferir, com mais precisão, os problemas e seus custos, revendo as expectativas de retorno dos projetos de transformação. O Quadro 10 ilustra esse processo.

Como pode ser visto no Quadro 1, esse processo é apresentado em etapas da Análise Ergonômica, o que é necessário para o Custeio. Inicialmente, na instrução da demanda, deve-se fazer a localização de problemas e avaliar-se a sensibilidade e elasticidade da estrutura. Nesse sentido, deve-se, também, verificar o cenário do problema. A análise do cenário pode ser dividida em duas etapas: i) identificar quais as perdas no processo, pela ausência da ergonomia e ii) avaliar quais os ganhos no processo, com o projeto de ergonomia. Obviamente, para se avaliarem os ganhos, devem-se avaliar as opções e a decisão de investimento. Após a implantação da solução, deve-se fazer o acompanhamento dos indicadores.

Aplicando o Método Ergonômico de Reconstrução Organizacional e Social (MEROS) (MAFRA, MATOS e VIDAL, 2003), a realidade é representada em camadas de matrizes, que se transformam em quadros dessa realidade. $\mathrm{O}$ Método estrutura-se a partir de uma matriz de inclusão dos aspectos observados, o custeio e a base da avaliação financeira da Ergonomia aparecem como novas camadas nesse conjunto de matrizes de análise do problema, em seus aspectos, impactos e desdobramentos.

Dessa forma, essas outras camadas que podem ser adicionadas ao conjunto de matrizes, farão referências aos investimentos necessários e ganhos de rentabilidade, dependendo da necessidade ou finalidade dos estudos que estarão sendo conduzidos.

Essas matrizes e expressões, com base nas Matrizes de inclusão, formam uma estrutura analítica. Essa estrutura é uma segmentação com uma hierarquização, em que são associadas camadas de inclusão de custos e, conseqüentemente, de investimentos necessários. Cada um dos ' $n$ ' componentes de aspectos "hierarquizados" do problema é classificado em categorias (p.ex. Equipamentos, Organização e Sistemas - EOS), e são atribuídos os custos como representação de um aspecto indicado e levantado na pesquisa (observação, conversa e análise de documentos).

\begin{tabular}{|c|c|c|c|}
\hline \multicolumn{2}{|c|}{ Análise de Ergonomia } & \multicolumn{2}{|c|}{ Custeio } \\
\hline & Etapa & Itens & Natureza do parâmetro \\
\hline \multirow{4}{*}{ 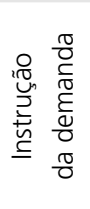 } & Demanda inicial & $\begin{array}{l}\text { Histórico e caracterização da empresa no } \\
\text { estado anterior (cenário amplo) }\end{array}$ & $\begin{array}{l}\text { Conjuntura econômica (macroeconomia), cenário } \\
\text { do setor e a posição da empresa }\end{array}$ \\
\hline & Análise global & Estimativa Inicial & Condições internas de operacionalidade \\
\hline & Reconstrução & Perspectivas de custo & Identificação de problemas \\
\hline & Demanda Ergonômica & Quadro de custos & Mapeamento de problemas \\
\hline \multirow{6}{*}{ 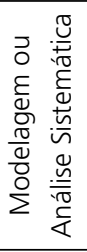 } & Focalização & \multirow{2}{*}{ Localização de problemas } & \multirow{2}{*}{ Determinação de focos de custos } \\
\hline & Pré-diagnóstico & & \\
\hline & \multirow{2}{*}{ Análise de Observáveis } & Indicadores & Quadro de indicadores \\
\hline & & Estudo dos impactos & Sensibilidade e elasticidade da estrutura \\
\hline & \multirow{2}{*}{ Modelo operante } & Índices & Cenário do problema \\
\hline & & Custos ergonômicos & Análise do cenário I: perdas no processo \\
\hline \multirow{3}{*}{ 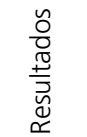 } & Validação & Alternativas para eliminação do problema & Análise do cenário Il: ganhos no processo \\
\hline & Proposições & Orçamento da solução & Opções e decisão de investimento \\
\hline & Projeto & Avaliação de resultados & Acompanhamento dos indicadores após a solução \\
\hline
\end{tabular}

Quadro 1 Relação entre AET, Itens de Custeio e natureza dos parâmetros 
Como pode ser visto no Quadro $2 \mathbf{0}$, ilustram-se os ' $n$ ' componentes de aspectos (custos relacionados, por exemplo) da atividade, em uma das camadas de inclusão de dados hierarquizados.

Cabe notar que, na parte de sínteses do quadro 2 , existe a síntese parcial, que agrega, por aspecto hierarquizado, a síntese subtotal, que diz respeito aos aspectos hierarquizados de um elemento de interface da Ergonomia, e a síntese geral, que agrega todos os aspectos, como um quadro do problema.

Ao quadro de características iniciais, que reúne dados referentes à situação, adicionam-se duas camadas. Uma, da coluna dos aspectos, é destinada a ser preenchida com a efetividade dos problemas e, a outra coluna, para os impactos, ou custos relacionados. Isso fica ilustrado no Quadro $3 \mathbf{0}$, de características iniciais da situação.

Partindo das relações que são estabelecidas pelas funções dos componentes de produção, em suas atividades de realização, pode-se deduzir alguns indicadores básicos da operação, indicadores da atividade. Ponderam-se os aspectos (operação, gestão e suporte) em seus vetores de efetividade. Com essas informações pode-se relacionar esse vetor ao quadro de indicações preliminares, para definir as características iniciais de custos associados à situação.

Conforme a matriz de características da situação vai sendo preenchida, os aspectos, então apontados, irão suscitar camadas superpostas, que têm nexos relacionais dessas características, com o desempenho do sistema de trabalho. São nexos ergonômicos em relações de custo da ausência de ergonomia e benefícios das soluções propostas.
Cada camada define dois vetores: o vetor (PN) de pontos notáveis $\left(\mathrm{pn}_{\mathrm{i}}\right)$, o que interfere nos resultados, e o respectivo vetor de custos (eficiência, eficácia e efetividade) relativos a perdas ergonômicas estimadas $\left(\mathrm{cp}_{\mathrm{i}}\right)$. Isso fica ilustrado a seguir.

Sendo:

$$
\left(\begin{array}{l}
P N=\left(p n_{1}, p n_{2}, p n_{3} \ldots p n_{n}\right) \\
C P=\left(c p_{1}, c p_{2}, c p_{3} \ldots c p_{n}\right)
\end{array}\right)
$$

em que: $\mathrm{PN}=$ Pontos Notáveis; formado pelos componentes $\left(\mathrm{pn}_{\mathrm{i}}\right)$, ou aspectos do problema; $\mathrm{CP}=$ Custos de Perdas, formado pelos componentes $\left(\mathrm{cp}_{\mathrm{i}}\right)$, ou custos de perdas estimadas.

As formas de abordar o problema dos pesos relativos aos elementos que formam os custos e os rendimentos, ou efetividades, são menos formais e requerem o mapeamento dessas preferências, pertinências, ou atributos de utilidade, permitindo comparações. Cada aspecto tem uma característica própria e requer um tipo de análise particular, que requer a participação de um grupo específico de pessoas (especialistas e trabalhadores). Nesse sentido, Zouguayrol e Almeida (1999), afirmam que, em epidemiologia e saúde, são usados modelos de multiatributos que trabalham com variáveis econômicas, de custos e retornos, não financeiras. Custos e retornos são transformados em escalas de utilidades usando $u\left(c_{i}\right), e u\left(r_{i}\right), i=1,2, \ldots n$, em que é aplicado o modelo de utilidade agregada, dado por:

$$
U=U\left[U_{I}(c, r), U_{2}(c, r) \ldots U_{n}(c, r)\right]
$$

\begin{tabular}{|c|c|c|c|c|c|c|c|c|c|}
\hline \multirow{2}{*}{$\begin{array}{l}\text { Matriz de aspectos e } \\
\text { prioridades }\end{array}$} & \multicolumn{3}{|c|}{ Equipamentos } & \multicolumn{3}{|c|}{ Organização } & \multicolumn{3}{|c|}{ Sistemas } \\
\hline & (1) & (2) & (3) & (1) & (2) & (3) & (1) & (2) & (3) \\
\hline situação 1 & $\mathrm{E} 1_{1}$ & $\mathrm{E} 2_{1}$ & $\mathrm{E}_{1}$ & $\mathrm{O} 1_{1}$ & $\mathrm{O}_{1}$ & $\mathrm{O}_{1}$ & $\mathrm{~S} 1_{1}$ & $\mathrm{~S} 2_{1}$ & $\mathrm{~S}_{1}$ \\
\hline situação 2 & $\mathrm{E} 1_{2}$ & $\mathrm{E} 2_{2}$ & $\mathrm{E}_{2}$ & $\mathrm{O}_{2}$ & $\mathrm{O}_{2}$ & $\mathrm{O}_{2}$ & $\mathrm{~S} 1_{1}$ & $\mathrm{SZ}_{2}$ & $\mathrm{~S}_{2}$ \\
\hline$\ldots$ & $\ldots$ & $\ldots$ & $\ldots$ & $\ldots .$. & $\ldots .$. & $\ldots .$. & $\ldots .$. & $\ldots .$. & $\ldots .$. \\
\hline situação $n$ & $\mathrm{E} 1_{n}$ & $\mathrm{E} 2_{n}$ & $\mathrm{E}_{n}$ & $\mathrm{O}_{n}$ & $\mathrm{O}_{n}$ & $\mathrm{O}_{n}$ & $\mathrm{~S} 1_{1}$ & $\mathrm{~S} 2_{n}$ & $\mathrm{~S} 3_{n}$ \\
\hline Síntese parcial & $\Sigma \mathrm{E}_{1}$ & $\Sigma \mathrm{E}_{2}$ & $\Sigma \mathrm{E}_{3}$ & $\Sigma \mathrm{O}_{1}$ & $\Sigma \mathrm{O}_{2}$ & $\mathrm{\Sigma O}_{3}$ & $\Sigma \mathrm{S}_{1}$ & $\Sigma \mathrm{S}_{2}$ & $\Sigma \mathrm{S}_{3}$ \\
\hline Síntese subtotal & \multicolumn{3}{|c|}{$\Sigma \mathrm{E}$} & \multicolumn{3}{|c|}{$\Sigma 0$} & \multicolumn{3}{|c|}{$\Sigma \mathbf{S}$} \\
\hline Síntese geral & \multicolumn{9}{|c|}{$\mathbf{S g}=\Sigma \mathrm{E}_{n}+\Sigma \mathrm{O}_{n}+\Sigma \mathrm{S}_{n}$} \\
\hline
\end{tabular}

Quadro 2

\begin{tabular}{|c|c|c|c|c|c|}
\hline \multirow{2}{*}{ Sigla } & \multirow{2}{*}{ Significado } & \multirow{2}{*}{ nível de atividade } & \multirow{2}{*}{ Sujeito } & \multicolumn{2}{|c|}{ Características Iniciais } \\
\hline & & & & aspectos & custos \\
\hline E & Equipamentos & artefatos & operacional & Operação & Eficiência \\
\hline 0 & Organização & sociofatos & estratégico & Gestão & Eficácia \\
\hline \multirow[t]{3}{*}{$\mathbf{S}$} & Sistemas & mentefatos & tático & Suporte & Efetividade \\
\hline & \multicolumn{3}{|c|}{ Sínteses parciais = } & & \\
\hline & \multicolumn{3}{|c|}{ Síntese geral = } & & \\
\hline
\end{tabular}

Matriz de aspectos e prioridades (Adaptado de Mafra e Vidal, 2000)

Quadro 3 | Quadro de características iniciais da situação 
em que: $U=$ utilidade agregada; $U=$ função utilidade; $u i=$ termo de utilidade relativo à solução de um aspecto $\mathrm{i} ; \mathrm{ci}=$ termo de custo relativo à solução de um aspecto $i$ e ri= termo de retorno relativo a uma solução de um aspecto i.

Nesse sentido, cada uma das ' $n$ ' combinações de $p n$ e $\mathrm{cp}_{\mathrm{i}}$ (ver equação 1), terá um correspondente $\mathrm{u}_{\mathrm{i}}$ (equação 2), como uma outra camada, relativo a um investimento na solução $\left(c_{i}\right)$ e retornos esperados $\left(r_{i}\right)$.

Numa estimativa inicial, o quociente das perspectivas de custos ergonômicos pelo custo total aponta a proporção da ausência de ergonomia, na empresa como um todo. Esse indicador de Razão da Demanda Inicial (RDI) engendra um debate com todos os agentes envolvidos, caracterizando a etapa metodológica de reconstrução da demanda.

O assunto tratado na reconstrução da demanda envolve desde o quadro de características, com o estado atual da empresa, o Quadro de Pontos Notáveis, que são as características da situação de trabalho, até as Perspectivas de Custos Ergonômicos, tomados como perdas no processo. A essência do debate é o reconhecimento de pontos notáveis e a importância relativa que lhes é atribuída, enquanto problemas.

É necessário um consenso acerca desses dois aspectos para se prosseguir na Ação Ergonômica. O resultado disso é a formação de um Quadro Básico da Situação.

Assim, definidos os elementos do Quadro Básico, insere-se a camada de custos, ou seja, estrutura-se o problema e, com o grupo de Ergonomia, calcula-se e prepara-se o quadro de perdas estimáveis, que já induz a um valor econômico para discussão com as pessoas da empresa. Isso está ilustrado, a seguir, no Quadro $4 \mathbf{0}$

Após esse debate, monta-se um quadro geral, com as características da situação e complementa-se com informação atualizada. Nesse estágio, que inclui as primeiras configurações das questões ergonômicas, dados de orçamentos e relatórios financeiros, são estimados os impactos da ausência da ergonomia, que podem ser confrontados com os elementos que constituíram a Razão da Demanda Inicial.

Esse quadro indicativo é apresentado para discussão e consenso com a diretoria da organização. Então, aos problemas consensuados podem ser estabelecidas análises sistemáticas para o aprofundamento das questões, no que consistirão as etapas subseqüentes. Isso fica ilustrado abaixo, onde se demonstra a matematização dessa passagem de reconstrução da demanda, nos esclarecimentos e ajustes dos aspectos de pontos notáveis, em suas camadas de aspectos de problemas no desempenho e por seus custos relativos, definindo a função de Demanda Ergonômica, na efetividade ergonômica do sistema.

Então, do Quadro inicial, que é dado pela equação (1) e, seguindo a Instrução da Demanda, resultará o Quadro da Demanda (QD), que será dado por:

$$
\left(\begin{array}{l}
Q P=\eta_{1}\left(p_{1}\right), \eta_{2}\left(p_{2}\right) \ldots \eta_{n}\left(p_{n}\right) \\
C E=\rho_{I}\left(c_{1}\right), \rho_{2}\left(c_{2}\right) \ldots \rho_{n}\left(c_{n}\right)
\end{array}\right)
$$

em que: $\mathrm{QP}=$ Quadro de problemas em seus valores de efetividade; $\mathrm{CE}=$ valores tangíveis de custos ergonômicos, ponderados por priorização consensuada; $\eta_{\mathrm{i}}=$ é o componente da função $(H)$ de relevância do aspecto do problema, em que $\mathrm{H}=\sum \eta_{\mathrm{i}}, \mathrm{j}=1,2 \ldots \mathrm{n} ; \rho_{\mathrm{j}}=$ é o componente função $(\mathrm{P})$ de prevalência de custos relativos a perdas ergonômicas, ou índice no orçamento, em que $\mathrm{P}=\sum \rho_{\mathrm{i}}$, j $=1,2 \ldots \mathrm{n}$.

Cabe lembrar que a prevalência de custos relativos a perdas ergonômicas $\left(\rho_{\mathrm{i}}\right)$, é uma função da relevância do aspecto do problema $\left(\eta_{\mathrm{i}}\right)$. Cada um dos componentes do problema $\eta_{\mathrm{j}}\left(\rho_{\mathrm{j}}\right)$ e seu respectivo custo $\rho_{1}\left(\mathrm{c}_{\mathrm{j}}\right)$, representa um aspecto da demanda, informando em termos de efetividade e custo. O conjunto vetor integrado pelos ' $n$ ' itens forma o quadro da demanda, nessa perspectiva.

Do Quadro da Demanda estabelecido, que significa a demanda estar instruída, considerando que a Demanda Ergonômica é definida por uma função gerencial, pode-se admitir, associados nessa função, um quadro de Custos Ergonômicos, ou perdas por aspectos de problemas, num Quadro de Problemas, que devem ser resolvidos.

De forma sintética, a estrutura analítica apresenta-se em camadas de aspectos notáveis. Esses aspectos revelam

\begin{tabular}{|c|c|c|c|c|}
\hline & Item & Definição & Ponto de impacto & Valor / período \\
\hline \multirow{3}{*}{$\begin{array}{l}\text { Perdas no } \\
\text { Funcionamento }\end{array}$} & Custo de pessoal & $\begin{array}{l}\text { Índices de ausência (absenteísmos e } \\
\text { afastamentos); }\end{array}$ & Custo de compensação & \\
\hline & \multirow{2}{*}{ Custo Operacional } & Gargalos, atrasos, & Lucro cessante em vendas & \\
\hline & & Perdas e refugos & Lucro cessante na planta & \\
\hline \multirow{5}{*}{$\begin{array}{l}\text { Perdas } \\
\text { suplementares }\end{array}$} & \multirow{2}{*}{ Custo de imagem } & Vendas & Lucro cessante & \\
\hline & & Qualidade & Lucro cessante & \\
\hline & \multirow{3}{*}{$\begin{array}{l}\text { Custos de encargos e } \\
\text { fiscalização }\end{array}$} & INSS & \multirow{2}{*}{ Notificação e multas } & \\
\hline & & Trabalhista & & \\
\hline & & Vigilância Sanitária & Parada, interdição e multa & \\
\hline & & & Total estimado & \\
\hline
\end{tabular}


interferências no desempenho e representam custos. A graduação, em termos de peso relativo no sistema, desses indicadores, diz respeito à relação de quanto é relevante, em relação com a prevalência, ou seja, o quanto de impacto de efetividade colabora ou interfere com os resultados, que no caso dessa análise, ocorre em termos de custos embutidos no processo (shadow costs).

Esse mesmo raciocínio é aplicado nas fases subseqüentes de modelagem operante e de soluções, aumentando o grau de precisão dos dados, guardadas as devidas diferenças de conteúdos de cada uma dessas outras fases. No caso das soluções, ao contrário das fases anteriores, verifica-se, não a prevalência do problema, mas o potencial de impactação como solução. Então, pode-se fazer uso da avaliação de custo e benefício, para prever expectativas de retornos dos projetos propostos.

De uma forma geral, num primeiro momento, evidenciam-se as condições em que esses custos estão aparecendo; num segundo momento, com o modelo operante, refinamse os elementos e os impactos da ausência da ergonomia, na forma de custos, dessa evidenciação, ao se focalizarem problemas; finalizando, no terceiro momento, faz-se uma avaliação das soluções que emergem, ou seja, do impacto das soluções naquele momento da organização. Assim, na seqüência de etapas da Análise de Ergonomia, os dados são estruturados e pontuados tanto pelo custeio da ausência de Ergonomia, quanto pelas avaliações de investimento.

\section{APLICAC̣̃̃O DA METODOLOGIA NO ESTUDO DE CASO}

O cenário no setor, do ramo de negócio da empresa, num plano mais amplo, era o do "apagão", ou seja, ocorria uma tendência recessiva, de infra-estrutura, nos recursos de eletricidade, que estavam escassos. O mercado em geral, naquele momento, para o setor, estava estável. No setor de alimentos há uma certa inelásticidade da demanda por produtos. Independente do preço, o consumo se mantém no mesmo nível.

A tendência recessiva estava se refletindo na economia brasileira como um todo e no ramo de negócios em questão percebia-se um fôlego na atividade das empresas ao estarem competindo. As bases produtivas dessa empresa eram fornos e equipamentos elétricos. Nessa conjuntura, recessiva para eletricidade, havia sido feito um investimento em dois novos fornos a gás. E a demanda de mercado estava em expansão.

$\mathrm{Na}$ reconstrução da demanda, obteve-se um consenso quanto à prioridade dos problemas, analisando os aspectos, as características, as conseqüências e os prazos de urgência. Num segundo momento, nas considerações da gerência, foi pautado que poderia haver um deslocamento da área dos escritórios na fábrica, que favoreceria o setor de produção em questão. Nesse sentido, a alteração no escritório era inevitável e o setor de produção tinha de ser mais bem pensado, com a pressão do seu mercado em expansão.

Dessa forma, chegou-se a uma demanda de ergonomia configurada pela análise de inter-relacionamento de setores complementares, com expressões e prioridades diferentes, num ambiente comum. Isso está ilustrado no Quadro $5 \mathbf{0}$. Ficou definido um primeiro nível da demanda por ergono- mia. Nesse momento, uma investigação mais detalhada da situação no setor de produção fez-se necessária.

\subsection{Aspectos Gerais da Produção}

Trata-se de uma indústria de processo de manufatura do setor de alimentos, ramo de cozinha industrial, localizada em área suburbana da cidade do Rio de Janeiro. É uma média empresa em expansão, que atende tanto ao mercado revendedor, como também dispõe de pontos de venda direta: atualmente são 12 unidades, com previsão de mais três pontos a serem integrados no corrente exercício.

Essa empresa tem seu ponto forte na distribuição direta e com importantes critérios de qualidade e de imagem. Seus produtos devem apresentar as mesmas características ao consumidor em qualquer hora e em qualquer ponto de venda, tanto quanto as encomendas devem encontrar, junto ao cliente, esses mesmos atributos de qualidade. O mercado é competitivo e as variações de qualidade impactam negativamente nas vendas. Nesse sentido, note-se que os produtos são perecíveis e de difícil estocagem (perda de características organolépticas, ou seja, alterações de sabor e composição). No que tange às encomendas, o risco de deterioração é bem menor já que a época de consumo é inteiramente determinada no pedido.

A base produtiva da empresa acompanhou, de forma apenas reativa, esse crescimento. Nesse sentido, o problema global da empresa é acertar sua planta industrial, para melhor atendimento desse perfil de demanda.

O setor da empresa selecionado para a Ação Ergonômica foi, portanto, sua planta industrial, que sustenta os pontos de venda da empresa. A planta, atualmente, já

\begin{tabular}{|c|c|c|c|c|}
\hline Natureza & aspecto & característica & conseqüência & Prazo \\
\hline de produção & quente & multiatividades & conflitos & Imediato \\
\hline organização & frio & multifunções & erros e riscos & Médio \\
\hline
\end{tabular}

Quadro 5 ॥ Síntese da análise dos problemas e seus prazos de urgência 
apresenta um elevado nível de produção. Essa unidade de desempenho permite avaliar os quantitativos de mão-deobra, as capacidades das diferentes máquinas assim como organizar os processos de escoamento.

Essa produção apresenta um panorama diversificado em termos de produto, preço básico de venda ao consumidor e a margem de contribuição de cada produto. Isso está detalhado no Quadro $6 \mathbf{0}$. O carro-chefe é integrado pelo subgrupo massas, sendo a fabricação de bolos a que representa a menor contribuição unitária.

\subsection{Estrutura e Organização da Produção}

Sua produção escoa-se, basicamente, por dois processos de venda: atendimento a encomendas (cliente externo) e suprimento dos pontos de venda direta (cliente interno). O setor industrial cumpre as missões de produção e de logística de escoamento - entrega, no caso de encomenda do mercado, e distribuição, reposição regular de estoques dos pontos de venda. Os pedidos são encaminhados ao setor pela administração, que apenas monitora o processo de entregas.

A empresa busca dois tipos de certificação, a primeira voltada para o aspecto 'produção', já que nesse setor a certificação ISO 9000 se revela excelente apoio para os negócios. Por outro lado, o setor de alimentos, em especial de cozinhas industriais é alvo de uma rigorosa fiscalização, tanto no aspecto sanitário como no aspecto trabalhista. A conformidade é uma das regências estratégicas dessa empresa.

Ainda nesses primeiros contatos foi apurado que a empresa tem grau de risco 3. Do ponto de vista previdenciário, sua contribuição situa-se na faixa de $3 \%$, a maior alíquota desse encargo. Por outro lado, são inúmeros os pequenos acidentes devidos a quedas e cortes, que provocam paradas e interrupções tecnicamente sem perda de tempo, mas com implicações no fluxo normal da produção.

\subsection{Características Iniciais}

Seguindo o método, foi montado o quadro de indicações preliminares, que sintetiza informações relevantes dessa etapa e traduz a informação fornecida pela gerência no início da ação ergonômica. Com esse quadro, buscaram-se informações para estabelecer a estimativa inicial de custos relacionáveis à ausência da ergonomia. Nesse sentido, seguindo a metodologia, foram feitas visitas, esta- belecidas conversas com interlocutores privilegiados, feitas observações diretas, foram coletadas informações complementares em documentos. Com essa base de informações, pôde-se evidenciar e foram amealhados os fatores de custos, indicados no Quadro 70.

O Quadro 7 é obtido com base nas observações do processo, estimativa de folha salarial e risco de interdição ou autuação trabalhista. Com essa estimativa, verificou-se uma perda mensal da ordem de $\mathrm{R} \$ 33.771,25$, considerando-se a situação central ligada à produção de bolos que totaliza 17.000 unidades mensais.

Para uma idéia inicial do estado de vários processos da empresa, foi possível estimar os vetores de Pontos Notáveis (PN) e de Custos de Perdas (CP), para um dos processos, e, com isso, estabelecer uma proporção de custos de perdas que, aplicada aos demais processos, permitiu extrapolar uma perspectiva de custo de perdas de toda a empresa. Nesse caso, o processo do bolo estava sendo observado e ficou estimado em 14,29\% de perdas nos custos de produção. E foi utilizada essa estimativa como uma Razão de Perdas que serviu de base para os demais processos.

Com base nessa estimativa, foi verificada uma Razão de perda ergonômica (Rpe) de 14,29\%, que, quando extrapolados para a fábrica, inferiu-se um valor inicial de $R \$$ 52.764,68, em perdas estimadas com a ausência de ergonomia, nessa cozinha industrial. Isso está ilustrado no Quadro 80

O objetivo dessa estimativa é apresentar uma ordem de grandeza para os problemas da empresa, com base na extrapolação da informação obtida num setor. Esse tipo de extrapolação é uma forma de generalizar a informação a um baixo custo de pesquisa. Isso é feito acreditando que se as coisas acontecem de uma determinada maneira num setor, devem acontecer de forma semelhante nos outros setores. Ou seja, provavelmente essa informação não se distancie muito da realidade e é obtida a um custo baixo.

\subsection{Analise Global e Demanda Ergonômica}

A planta do setor de confeitos serviu como base para se perceberem algumas características. Dentre elas, a reconstrução da demanda apontou o setor de cocção da confeitaria, que considerando sua estrutura atual, apresenta um gargalo de produção, um problema de manuseio de matéria-prima com implicação na higiene, um problema de espaço físico e um problema de contrante térmica.

\begin{tabular}{|c|c|c|c|c|c|c|}
\hline \multirow{2}{*}{ Produto } & \multirow{2}{*}{ Produção } & \multirow{2}{*}{ Preço unitário } & \multirow{2}{*}{ Faturamento } & \multicolumn{2}{|c|}{ Margem de lucro } & \multirow{2}{*}{ Custo/produção } \\
\hline & & & & Valor & $\%$ & \\
\hline bolos & 17000 & $\mathrm{R} \$ 22,30$ & $R \$ 379.100,00$ & $\mathrm{R} \$ 8,40$ & $37,67 \%$ & $\mathrm{R} \$ 236.300,00$ \\
\hline massas & 20000 & $R \$ 10,90$ & $\mathrm{R} \$ 218.000,00$ & $\mathrm{R} \$ 6,67$ & $61,17 \%$ & $\mathrm{R} \$ \quad 84.649,40$ \\
\hline doces & 9000 & $\mathrm{R} \$ \quad 3,50$ & $\mathrm{R} \$ \quad 31.500,00$ & $\mathrm{R} \$ 1,87$ & $53,42 \%$ & $\mathrm{R} \$ \quad 14.672,70$ \\
\hline outros & 6500 & $\mathrm{R} \$ 12,40$ & $\mathrm{R} \$ 80.600,00$ & $\mathrm{R} \$ 7,23$ & $58,34 \%$ & $R \$ 33.576,35$ \\
\hline \multicolumn{3}{|r|}{ Totais } & $R \$ 709.200,00$ & & & $R \$ 369.198,45$ \\
\hline
\end{tabular}




\begin{tabular}{|c|c|c|c|}
\hline Custo & Definição & Ponto de impacto & Valor / mês \\
\hline & \multicolumn{3}{|c|}{ Custos de Funcionamento } \\
\hline de pessoal & $\begin{array}{l}\text { Calculado dos índices de absenteísmos } \\
\text { e afastamentos produzidos pela ausência } \\
\text { de ergonomia nos processos; }\end{array}$ & Custo de compensação & 966,59 \\
\hline \multirow{2}{*}{ operacional } & Gargalos, atrasos, & Lucro cessante nos PVD's & $21.632,56$ \\
\hline & Perdas e refugos & Lucro cessante na planta & $7.140,00$ \\
\hline & \multicolumn{3}{|c|}{ Custos suplementares do mau funcionamento } \\
\hline \multirow[t]{2}{*}{ de imagem } & $\begin{array}{l}\text { Quebra de disponibilidade de } \\
\text { produtos nos PVD's }\end{array}$ & Lucro cessante nos PVD's & $1.528,00$ \\
\hline & Variação da qualidade nos PVD's & Lucro cessante nos PVD's & 504,00 \\
\hline \multirow{3}{*}{$\begin{array}{l}\text { de encargos } \\
\text { e fiscalização }\end{array}$} & INSS & Margem de $3 \%$ podendo ser baixada para $2 \%$ & 53,40 \\
\hline & Trabalhista & Notificação e multas & $1.489,74$ \\
\hline & Vigilância Sanitária & Parada ou interdição com multa & 456,96 \\
\hline & & $\begin{array}{ll}\text { Total estimado } \\
\end{array}$ & $33.771,25$ \\
\hline
\end{tabular}

Quadro 7 Quadro de perdas estimáveis a partir da DG

\begin{tabular}{|c|c|c|c|}
\hline Produto & CUSTO R\$/Produto & PCE & Rpe \\
\hline bolos & $236.300,00$ & $33.771,25$ & $14,29 \%$ \\
\hline massas & $84.649,40$ & $12.097,83$ & \multirow{4}{*}{$(14,29 \%)$} \\
\hline doces & $14.672,70$ & $2.096,98$ & \\
\hline outros & $33.576,35$ & $4.798,62$ & \\
\hline Totais $(R \$)=$ & $369.198,45$ & $52.764,68$ & \\
\hline
\end{tabular}

Quadro 8 | Perspectiva de custos ergonômicos e Rpe

Em função do momento da empresa (expansão com manutenção de padrões de higiene, qualidade e produtividade), a demanda inicial encaminhou-se em torno de problemas de maior peso no custo de operação da instalação atual, ou seja, dos problemas de Organização. Especialmente ficaram mais latentes os problemas de organização espacial. As visitas subseqüentes, assim como o processo de coleta de dados, permitiu a construção de um quadro dos problemas (ver Quadro $9 \mathbf{0}$ ).

\begin{tabular}{|l|l|l|}
\hline \multirow{5}{*}{ Natureza } & $(\mathbf{P})$ & Problemas \\
& $\left(p_{1}\right)$ & Exposição a choques térmicos \\
\cline { 2 - 3 } & $\left(p_{2}\right)$ & Exaustão precária \\
\cline { 2 - 3 } & $\left(p_{3}\right)$ & chão molhado \\
\cline { 2 - 4 } & $\left(p_{4}\right)$ & manipulação de panelas \\
\cline { 2 - 4 } & $\left(p_{5}\right)$ & sujeitos a queimaduras e cortes \\
\cline { 2 - 4 } & $\left(p_{6}\right)$ & Bancadas sem amparos \\
\cline { 2 - 4 } & $\left(p_{7}\right)$ & Falta de apoio (descanso) para tarefas \\
\hline \multirow{5}{*}{ Organização } & $\left(p_{8}\right)$ & Estoque de utensílios e matérias primas \\
\cline { 2 - 3 } & $\left(p_{9}\right)$ & cruzamento de linhas \\
\cline { 2 - 3 } & $\left(p_{10}\right)$ & Conflitos de circulação na área \\
\hline \multirow{5}{*}{ Sistema } & $\left(p_{11}\right)$ & procedimento na manipulação de ingredientes: \\
\cline { 2 - 3 } & $\left(p_{12}\right)$ & \\
\cline { 2 - 3 } & $\left(p_{13}\right)$ & \\
\cline { 2 - 3 } & $\left(p_{14}\right)$ & riscos pessoais de micoses \\
\hline & $\left(p_{15}\right)$ & fadiga das mãos e ombros \\
\hline
\end{tabular}

Quadro 9 Problemas encontrados 


\subsection{Modelagem Operante}

O foco sobre a organização presidiu a focalização da demanda e encaminhou uma análise mais detalhada das atividades e dos recursos da unidade de confeitos. Essa envolve a confecção de bolos, recheios e mousses, doces finos, massas de doces e lavagem, envolvendo além da área quente (fornos, fogões), uma área fria (ambientes de geladeiras e congeladores) e uma área particular, que passou a ser denominada de área úmida, integrada por equipamentos e processos para a limpeza dos insumos materiais da unidade (formas e utensílios de confeitaria).

A organização da produção, para as equipes de trabaIho, é feita com equipes em rodízio de pessoal de acordo com as características dos trabalhadores e as necessidades de produção. Existem critérios ("objetivos") para o rodízio ou colocação de um funcionário em um posto e/ou outro. A demanda da atividade é que rege a colocação.

A Análise sistemática evidenciou uma série de problemas cuja origem se situava no agenciamento dessa área úmida. Sua localização no centro da área de circulação, entre as áreas quente e fria, implicava em forte interferência executiva. Por outro lado, o processo de lavagem é absolutamente central dado que viabiliza insumos materiais básicos para todas as atividades da unidade de confeitos.

As características, apontadas na demanda ergonômica, foram observadas e classificadas por sua natureza de problemas (EOS) e seus aspectos ponderados (pj) em termos de suas efetividades (\%) enquanto agravantes dos problemas. Foram reportadas, dessa forma, após entendimento com a gerência, especialistas e operadores, como está apresentado mais adiante.

Com a sistematização do problema, chegou-se ao exposto no Quadro $10 \boldsymbol{0}$. Como se pode observar nesse quadro, para os problemas de natureza "Equipamentos"; che- garam-se aos seguintes valores: (p1) Exposição a choques térmicos (1\%); (p2) Exaustão precária (1\%); Riscos físicos: (p3) chão molhado (60\%); (p4) manipulação de panelas quentes e pesadas (16\%); ( $p 5)$ sujeitos a queimaduras e cortes (1\%); (p6) Bancadas sem amparos para as rebarbas (cortes de bolos) (20\%); (p7) falta de apoio (descanso) para tarefas que exigem longa duração numa mesma postura $(18 \%)$.

Para os problemas de natureza da Organização, chegou-se aos seguintes valores: (p8) organização inadequada para o armazenamento dos utensílios e matérias-primas (estoque da cozinha) (12\%); (p9) má distribuição dos processos com cruzamento de linhas (25\%); (p10) conflitos de circulação na área de trabalho (74\%).

E, para os problemas de natureza de Sistema ou cognitivos, chegou-se aos seguintes valores: (p11) não existe um procedimento na manipulação de vários ingredientes (13\%); ( 12 ) riscos pessoais de micoses (5\%); (p13) fadiga das mãos e ombros (18\%), bem como implicações na (p14) qualidade do produto final (35\%) e (p15) nos padrões sanitários (19\%).

Para efeito de apuração de custos, o quadro foi reordenado por efetividade e custo dos problemas. Assim, calculou-se o custo potencial, que reflete o montante de custos que a situação poderia vir a engendrar. Nessa apreciação, os custos internos, especialmente os referentes aos gargalos, aparecem como os de mais forte implicação sobre a efetividade. Partindo dessa apreciação estruturou-se um quadro de Efetividade (\%) de problema e tipo de custo.

Em seguida, foram aplicadas as ponderações advindas do vetor de efetividades propiciado pelo Modelo Operante. Os resultados integram o Quadro 10, a seguir. Observouse que o custo de imagem resultante dos conflitos de circulação, tem implicações externas de qualidade. No plano

\begin{tabular}{|l|c|c|l|l|c|}
\hline \multicolumn{2}{|c|}{ Problemas (pj) e Efetividade (\%) } & \multicolumn{3}{c|}{$(\% \times$ X Custo R\$) interno + externo } \\
\hline Característica (código) & & $\%$ & interno & externo & valor (R\$) \\
conflitos de circulação & $(\mathrm{p} 10)$ & 74 & gargalo & imagem & 17.511 \\
\hline implicações na qualidade & $(\mathrm{p} 14)$ & 35 & gargalo & imagem & 8.282 \\
\hline cruzamento de linhas & $(\mathrm{p} 9)$ & 25 & gargalo & imagem & 5.916 \\
\hline procedimento manipulação & $(\mathrm{p} 11)$ & 13 & gargalo & sanitária & 2.871 \\
\hline estoque na área & $(\mathrm{p} 8)$ & 12 & gargalo & imagem & 2.896 \\
\hline bancadas sem amparos & $(\mathrm{p} 6)$ & 20 & perdas & trab. & 1.725 \\
\hline panelas quentes e pesadas & $(\mathrm{p} 4)$ & 16 & perdas & trab. & 1.380 \\
\hline chão molhado & $(\mathrm{p} 3)$ & 60 & pessoal & trab. & 1.473 \\
\hline nos padrões sanitários. & $(\mathrm{p} 15)$ & 19 & pessoal & sanitária & 270 \\
\hline falta de apoio (descanso) & $(\mathrm{p} 7)$ & 18 & pessoal & trab. & 442 \\
\hline fadiga das mãos e ombros & $(\mathrm{p} 13)$ & 18 & pessoal & trab. & 442 \\
\hline riscos de micoses & $(\mathrm{p} 12)$ & 5 & pessoal & santiária & 71 \\
\hline choques térmicos & $(\mathrm{p} 1)$ & 1 & pessoal & trab. & 27 \\
\hline exaustão precária & $(\mathrm{p} 2)$ & 1 & pessoal & trab. & 24 \\
\hline queimaduras e cortes & $(\mathrm{p} 5)$ & 1 & pessoal & trab. & 24 \\
\hline & & & & Total = & $\mathbf{4 3 . 3 6 1}$ \\
\hline
\end{tabular}


interno, é relevante sublinhar que a demanda gerencial apontava que a questão de organização, de procedimentos e estoques na área, são problemas menores, com a ponderação aplicada.

Com essa nova perspectiva de custos ergonômicos, pôde-se recalcular a perspectiva global da empresa (ver quadro 3). Nesse sentido, o custo ergonômico desse setor passou a representar $18.35 \%$ do custo de produção. Considerando essa proporção como uma tendência da organização, quando esse valor fica extrapolado para os outros setores da empresa, a ausência de Ergonomia na empresa representa um custo de $\mathrm{R} \$ 67.748,44$. Isso está ilustrado no Quadro $11 \boldsymbol{O}$, que mostra a correção da perspectiva de perdas por ausência de Ergonomia.

É interessante notar que a diferença entre perspectiva e apuração se situa em torno de $30 \%$ a maior da estimativa que se pode fazer quando da demanda gerencial e que corresponde à possibilidade que tem a gerência de não perceber seus custos. A partir desse quadro, pode-se mostrar que a ausência da ergonomia está efetivamente onerando mensalmente a empresa, neste setor, em $\mathrm{R} \$$ 67.748,44.

\subsection{Alternativas de Solução}

Do exposto no Quadro 10, e em face do processo de validação junto à empresa, foram examinadas as alternativas de melhoria segundo o quadro de deliberação (Quadro 12 )). De acordo com esse quadro, pode-se dizer que as ações corretivas (grupo I), embora de baixo custo, pouco impacto produzem no sentido de atenuar os custos da ausência da Ergonomia nos processos da empresa. As ações de remanejamento (grupo II), têm um custo de investimento um pouco mais alto e produzem em efeito moderado. Já as ações de atualização de instalações (grupo III), representam um custo de investimento mediano, com alto impacto no problema central.

O processo de validação mostrou que todas as recomendações acima podem vir a ser adotadas. As indicações de melhoria que compõem os grupos I e II, são de simples execução e praticamente envolvem previdências. No entanto, as recomendações do grupo III, de certo modo, as precedem e as englobam. Assim, passa-se a orientar análises para as mudanças desse grupo III. De acordo com esse quadro, pode-se dizer que as ações corretivas, embora de baixo custo, pouco impacto produzem no sentido de atenuar os custos da ausência da Ergonomia nos processos da empresa.

A proposta de rearranjo básico foi isolar a Área úmida dos outros processos. Com as mudanças aqui preconizadas, suprimem-se os problemas mais contundentes, na formação do custo ergonômico apurado: conflitos na circulação, inadequações na qualidade e cruzamentos de linhas, que representam, respectivamente, $74 \%$ (p10), 35\% (p14) e $25 \%$ (p9), dos impactos em custos.

A proposta final, que inclui tanto as providências (grupos I e II), como as mudanças físicas (grupo III), ficou orçada em $R \$ 33.250,00$, já incluídos os custos de

\begin{tabular}{|l|c|c|c|}
\hline Produto & CUSTO R\$ / Produto & PCE & Rpe \\
bolos & $236.300,00$ & $43.361,57$ & $\mathbf{1 8 . 3 5 \%}$ \\
\hline massas & $84.649,40$ & $15.533,17$ & \\
\cline { 1 - 3 } doces & $14.672,70$ & $2.692,44$ & \multirow{2}{*}{$(18.35 \%)$} \\
\cline { 1 - 3 } outros & $33.576,35$ & $6.161,26$ & \\
\cline { 1 - 3 } Totais $(\mathrm{R} \$)=$ & $\mathbf{3 6 9 . 1 9 8 , 4 5}$ & $\mathbf{6 7 . 7 4 8 , 4 4}$ & \\
\cline { 1 - 3 } & & & \\
\cline { 1 - 3 } & & &
\end{tabular}

Quadro 11 Correção de perdas por ausência de Ergonomia

\begin{tabular}{|c|c|c|c|c|}
\hline \multirow{2}{*}{ 울 } & \multirow[b]{2}{*}{ Recomendações } & \multirow{2}{*}{$\begin{array}{c}\text { Tipo de } \\
\text { alternativa }\end{array}$} & \multicolumn{2}{|c|}{ Nível } \\
\hline & & & $\begin{array}{l}\text { Investimento } \\
\text { necessário }\end{array}$ & $\begin{array}{l}\text { Benefício } \\
\text { Esperado }\end{array}$ \\
\hline \multirow{2}{*}{$\mathbf{I}$} & Levantamento de produtos químicos para desencrustar & \multirow{2}{*}{ Corretiva } & \multirow{2}{*}{ Baixo } & \multirow{2}{*}{ Baixo } \\
\hline & Óculos de proteção & & & \\
\hline \multirow{5}{*}{ II } & Água Quente no posto de lavagem & \multirow{5}{*}{ Remanejamento } & \multirow{5}{*}{ Médio } & \multirow{5}{*}{ Médio } \\
\hline & Aumento da profundidade da bancada & & & \\
\hline & Aumento da cuba & & & \\
\hline & Torneira que tenha mobilidade & & & \\
\hline & Pistola de água & & & \\
\hline \multirow{4}{*}{ III } & Isolamento da área de lavagem & \multirow{4}{*}{ Modernização } & \multirow{4}{*}{ Alto } & \multirow{4}{*}{ Alto } \\
\hline & Box para utensílios pesados (Com regulagem de altura e acesso) & & & \\
\hline & Aumento de espaço para estoque de utensílios sujos & & & \\
\hline & Refazer o layout & & & \\
\hline
\end{tabular}


consultoria e projeto (subvalor de $\mathrm{R} \$ 20.600,00$ ). A esses valores devem ser acrescidos os custos econômicos da parada de produção, quando a obra for executada. Esses custos se repartem em duas categorias: (a) o custo de formação de estoque regulador e (b) o custo de pessoal em parada técnica.

A recomendação foi a de realizar a obra (de pequenas proporções), para o que se estimou sua realização em quatro dias consecutivos. A estratégia temporal consistiu, ainda, em realizá-la próximo a um feriado, situação em que a empresa já pratica formação de estoques reguladores de forma incorporada. Embora o custo final da mão-de-obra seja onerado em cerca de $40 \%$ nos feriados, os custos marginais de parada técnica e formação de estoque, compensam esse acréscimo. Nessa estratégia, há que se considerar pelo menos dois dias parados, estoque suplementar para três dias e um suplemento de três dias sobre quatro para efeito da apropriação de custos de construção e reforma.

\subsection{Avaliação do Investimento}

Para avaliar o investimento, por se tratar de um projeto simples e de rápida implantação, adotaram-se três métodos de análise, que partiram da definição do Fluxo de Caixa Descontado (FCD) do projeto, quais sejam: o do Valor Presente Líquido (VPL), o da Taxa Interna de Retorno (TIR), a adição de valor sobre o custo de oportunidade da empresa e o do Payback Period descontado, tempo de retorno do investimento, ou Ponto de Equilíbrio (PE). Para isso, algumas questões surgem. Em primeiro, como os benefícios serão percebidos na empresa e, em função disso, qual a regra de amortização a ser adotada? (ROSS, WESTERFIELD e JAFFE, 2002)

Na primeira questão, foi estimado que, num primeiro momento, o impacto dos benefícios, nesse caso, correspondeu a $64 \%$ das perdas. Assim, o nível de perdas da empresa, ou Custo Ergonômico, que estava na ordem de R\$ 67.750/mês, serviu de base para esse cálculo (R\$2.258/ dia),ou seja, os benefícios, no primeiro momento, foram $64 \%$ de $R \$ 2.258 /$ dia $=R \$ 1.445 /$ dia.

Quanto à segunda questão, a regra de amortização que foi sugerida seguiu o parâmetro dado pela própria apuração de perdas pela ausência da Ergonomia, em relação ao investimento necessário para a solução dos problemas, à medida que o Orçamento Total (OT - linha perpendicular ao eixo $R \$$, na Figura 1) resultou em um investimento de $R \$ 33.250,00$ e o rendimento na ordem de $R \$ 1.445 /$ dia.

Iniciou-se a avaliação com o Valor Presente Líquido e pôde-se concluir que, num fluxo de caixa descontado (taxa de oportunidade de $0,5 \%$ dia, ou $15 \%$ mês), o projeto gera em três meses (60 dias úteis) um resultado em Valor Presente Líquido de R\$41.151,00. Ou seja, Valor Presente Líquido positivo e bastante favorável, ainda mais se for levado em conta que a vida útil desse projeto vai muito além dos três meses avaliados. É importante assinalar a alta taxa de retorno dos investimentos em Ergonomia.

A Taxa Interna de Retorno do projeto, nesse caso, correspondeu a uma taxa próxima de $4,2 \%$ ao dia, o que projeta uma taxa de aproximadamente $126 \%$ ao mês (30 dias). É importante notar que a adição de valor econômico, nesse caso, foi de $3,7 \%$ ao dia, sobre o custo de oportunidade da empresa (15\%/mês). Isso está ilustrado no Quadro $13 \mathbf{O}$.

Quanto ao período de recuperação do investimento, foi utilizado o fluxo de caixa descontado (taxa de 0,5\% dia, ou $15 \%$ mês). Obteve-se como resultado, para esse investimento, seu ponto de equilíbrio (PE), ou seja, paga-se integralmente em 26 dias, com apenas $64 \%$ dos benefícios. Isso pode ser visto graficamente na Figura $1 \boldsymbol{0}$. Pode-se observar que no vigésimo sexto dia (ponto PE, no encontro das retas RI e OT), o investimento estará pago, ou seja, esse é o período de recuperação do investimento (trecho (a) da reta RI), a partir daí (trecho (b) da reta RI), serão rendimentos diários de $R \$ 1.445$, ou $4 \%$ ao dia, com a eliminação de 64\% do Custo Ergonômico (CE).

\begin{tabular}{|c|c|c|c|c|c|}
\hline Orçamento & Custo ergonômico & \multicolumn{2}{|c|}{ Retorno do projeto } & \multicolumn{2}{|c|}{ Valor Adicionado do projeto } \\
Total (OT) & (CE/dia) & 30 dias & dia & Oportunidade & V.A. \\
\hline R\$ 33.250 & R\$ 1.445 & $126 \%$ & $4.2 \%$ & $0,5 \% / d i a$ & $3,7 \%$ \\
\hline
\end{tabular}

Quadro 13 | Orçamento, custo ergonômico e retorno do investimento

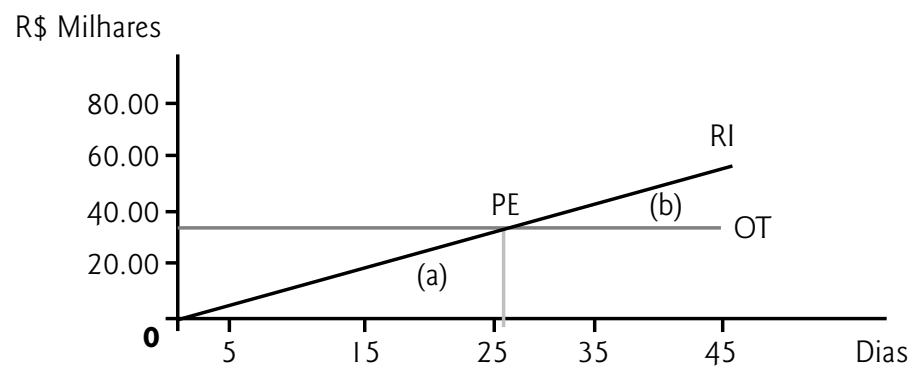

Figura 1

Ponto de Equilíbrio da Ação Ergonômica no caso 
Altos índices de retorno nos investimentos em Ergonomia, como se confirmou nesse caso, estão presentes em muitos dos casos relatados na literatura e comunicados nos congressos e eventos da área. Naturalmente, esse caso é particular e não caberia generalizar ou propor um indicador de retorno. No entanto, as grandes corporações têm buscado esse tipo de referencial para seus processos de negócio.

\section{DISCUSSÃO}

Dois pontos serão tratados nessa discussão. Esses são: o problema da composição dos indicadores dentro de uma lógica formal, ou de uma lógica menos formal; e a questão que diz respeito ao problema do mapeamento, dentro de uma construção social, na pertinência dos pesos relativos e na importância relativa de quem determina o grau da preferência e pertinência do atributo.

Quanto à composição dos indicadores, ela mesma encontra alguns problemas do ponto de vista da lógica formal ou booleana. A diferença fundamental é que a lógica booleana resulta sempre em 0 ou 1, que é chamada de característica. Os modelos de utilidade são mais abrangentes, permitindo variáveis não quantitativas (ZOUGUAYROL e ALMEIDA, 1999). Por outro lado, a lógica fuzzy trabalha com a noção de pertinência, que é um valor que é assumido em contexto e estará, comparado ao proposto anteriormente, assumindo quaisquer valores entre 0 e 1 (YAGER e FILEV, 1994).

Quanto à construção sociocultural, o problema do mapeamento aparece tanto na pertinência dos pesos relativos em si, quanto na importância relativa (nível na cadeia de decisão) de quem determina o grau da preferência e pertinência de um atributo. Assim, perguntas tais como: que atributos sobre que períodos de tempo são importantes? As preferências de quem são importantes? Qual a importância relativa de cada conjunto de preferências? devem ser respondidas. As respostas a essas perguntas são extremamente dependentes do contexto.

\section{CONCLUSÃO}

Como foi demonstrado neste artigo, a Ergonomia pode ser aliada ao sistema da Qualidade, quando colocada como uma base para o requisito de melhoria contínua. Ao colocar o ser humano no centro do processo, preservando a integridade física e mental dos trabalhadores, curiosamente, geram-se benefícios efetivos (produtividade e qualidade de vida) para os processos de produção.

Essa metodologia de custeio mostra como os problemas no desempenho acabam impactando no negócio, numa expressão econômica, caracterizados pelas questões de saúde e qualidade de vida no trabalho. A chave desse resultado está na associação de descrições com indicadores reportados nas desconformidades no processo de trabalho, o que supõe o exame das formas que permitam atingir as conformidades. A opção de localizar indicadores nas subjacências das queixas e comentários dos operadores, bem como dos demais agentes do sistema e que se faz aparecer de forma inequívoca no modelo operante, é o efeito produzido pela aplicação da metodologia da Análise Ergonômica. Isso significa a existência de aspectos que afetam o desempenho econômico global do negócio, que estão, normalmente, fora do controle gerencial.

A fala do trabalhador sempre expressa temas de saúde e qualidade de vida, o que a AET permite incluir sem quaisquer problemas. Essas falas têm, também, um significado econômico, o que permite fazer a transposição desses temas para o domínio do negócio, de forma bastante pertinente. Num jogo de palavras, dá-se, efetivamente, valor ao que falam os operadores.
A preocupação foi confrontar um problema de gestão (as perdas e o investimento de correção), com uma perspectiva da Ergonomia (o projeto e a análise de sistemas de trabalho) e de economia (recuperação do valor agregado nas atividades de trabalho). Como a tomada de decisão requer a transposição dos indicadores para o domínio do negócio, todo o método se assentou na percepção dos nexos relacionais provindos das queixas e comentários dos operadores e agentes do sistema, expressos nos indicadores que foram construídos. Se a vantagem descritiva do método AET estava em apontar as causas, nas raízes dos problemas, a proposta permite elaborar essas redes de causalidades e as equações de custos ergonômicos e confrontá-las com investimentos necessários para as soluções.

Nesse sentido, acredita-se ter contribuído com o estado das práticas, ao sinalizar as desconformidades em si, ao sinalizá-las como resultante de um funcionamento do sistema de produção em modo degradado, tratando de proposições e projetos e avaliando a viabilidade da solução a partir de um método que combina os rigores da Análise de Ergonomia, da Economia e da análise financeira.

No caso apresentado, a ausência de ergonomia pôde ser caracterizada por indicadores econômicos de efetividade e pelo efeito no estado atual da empresa. Isso permitiu, mediante a Análise Ergonômica do Trabalho, a focalização e a solução de algumas dificuldades e problemas que afetavam seu desempenho. O cruzamento entre aspectos ergonômicos e de desempenho, é que permite produzir tais indicadores. 


\section{Referências Bibliográficas}

AKERBOOM, S.P.; KRUYSSE, H. W.; LAHEIJ, W.. Rear light configurations: the removal of ambiguity by a third brake light. 1993. In: Vision in Vehicles, Gale, A. G., Brown, I.D., Haslegrave, C.M., Kruysse, H. W., Taylor, S. P. (eds.), Vol. IV. North-Holland, Amsterdam, p.129-138. ALEXANDER, D.C.. The Economics of Ergonomics, Part II. In: Proceedings of the HFES 39th Annual Meeting, v. 2, 1995.

BEEVIS, D.; SLADE, I. M.. Ergonomics-costs and benefits. Appl. Ergon. 1, 1970, p. 79-84.

Ergonomics Costs and Benefits Revisited, p. 491-496, v. 34, Issue 5, September, 2003, Applied Ergonomics Elsevier Ltd.

BUDंNICK. Economics Through Ergonomics. ErgoWeb ${ }^{\circledR}$ Inc. Midway. UT, USA, 1998.

HENDRICK, Hal W.. Measuring the Economic Benefits of Ergonomics Error Analysis, Inc., USA, 1997

Determining the cost-benefits of ergonomics projects and factors that lead to their success, p. 419-427, v. 34, Issue 5, September, 2003, Applied Ergonomics Elsevier Ltd.

IEA/HFES. Internacional Definition of Ergonomics. In: Proceedings of the IEA/HFES 13th Trieannual Meeting, 2000.

IUDÍCIBUS, Sérgio de. A gestão estratégica de custos e a sua interface com a contabilidade gerencial e a teoria da contabilidade: uma análise sucinta. Conferencias nos anais do IV CONGRESSO INTERNACIONAL DE CUSTOS e II CONGRESSO BRASILEIRO DE GESTÃO ESTRATÉGICA DE CUSTOS. São Paulo, SP, 1995.

KIRWAN, Barry. An overview of a nuclear reprocessing plant Human Factors programme, p. 441-452, v. 34, Issue 5, September, 2003, Applied Ergonomics Elsevier Ltd.

KRAGT, H.. Enhancing Industrial Performance. Taylor \& Francis, London, 1992.

MACLEOD, Iain S.. Real-world effectiveness of Ergonomic methods, p. 465-477, v. 34, Issue 5, September, 2003, Applied Ergonomics Elsevier Ltd.

MAFRA. J. R. D.. Economia da Ergonomia: Metodologia de Custeio Baseado no Modelo Operante. 2004. Tese de Doutorado, Programa de Engenharia de Produção, COPPE/UFRJ.

; MATOS; VIDAL, M. C. R.. MEROS e o ciclo PETRA de pesquisa. Nota Técnica, GENTE/COPPE/UFRJ, 2003.

; SILVA, M.. Análise Ergonômica do Trabalho de uma cozinha industrial: setor de massas e recheios. Monografia do Curso de Especialização Superior em Ergonomia (CESERG), GENTE/COPPE/UFRJ, 2001.

; VIDAL, M. C. R.. Considerações Econômicas sobre a Intervenção Ergonômica: Alguns Conceitos e Benefícios. Artigo completo nos Anais do X CONGRESSO BRASILEIRO DE ERGONOMIA, ABERGO. Rio de Janeiro - RJ, 2000.

Inovação e Ergonomia: novos produtos, novos processos ou novos paradigmas. Artigo completo nos Anais do XII CONGRESSO BRASILEIRO DE ERGONOMIA, ABERGO. Recife - PE, 2002.

MCKNIGHT, A.J.; SHINAR, D.. Brake reaction time to center high-mounted stop lamps on vans and trucks. Human Factors 34, p.205-213, 1992. NESS, Joseph A.; CUCUZZA, Thomas G.. Tapping the full potential of ABC. Harvard Business Review, July-August, 1995.

NR 17 Ergonomia. Normas Regulamentadoras do Ministério do Trabalho e Emprego.

OXENBURGH, Maurice S.. “Cost Benefit Analysis of Ergonomics Programs.” 150 AIHA JOURNAL (58) February, 1997.

; MARLOW, Pepe; OXENBURGH, Andrew. “Increasing Productivity and Profits through Health and Safety.” CRC Press, 2004.

PETENATE, Ademir José. A gestão estratégica de custos e a sua interface com a contabilidade gerencial e a teoria da contabilidade: uma análise sucinta. Conferencias nos anais do IV CONGRESSO INTERNACIONAL DE CUSTOS e II CONGRESSO BRASILEIRO DE GESTÃO ESTRATÉGICA DE CUSTOS. São Paulo, SP, 1995.

ROSS, Stephen; WESTERFIELD, Randouph; JAFFE, Jeffrey. Administração Financeira: corporate finance. São Paulo, S.P.: Atlas, 2002.

SEELEY, Patricia A.; MARKLIN, Richard W.. Business case for implementing two ergonomic interventions at an electric power utility, p. 429439, v. 34, Issue 5, September 2003, Applied Ergonomics Elsevier Ltd.

SEN, Rabindra Nath; YEOW, Paul H. P., 2003. Cost effectiveness of ergonomic redesign of electronic motherboard, p.453-463, v. 34, Issue 5, September, 2003, Applied Ergonomics Elsevier Ltd.

STANTON, Neville A.; BABER, Christopher. On the cost-effectiveness of ergonomics, p. 407-411, v. 34, Issue 5, September, 2003, Applied Ergonomics Elsevier Ltd.

; YOUNG, Mark S.. Giving ergonomics away? The application of ergonomics methods by novices, p. 479-490, v. 34, Issue 5, September, 2003, Applied Ergonomics Elsevier Ltd.

ZOUGUAYROL, M.Z.; ALMEIDA F.. Epidemiologia e Saúde, 1999.

YAGER; FILEV. Essentials of Fuzzy Modeling and Control. Wiley-Interscience, 1994.

YIN, Robert K.. Estudo de Caso - Planejamento e Métodos. Porto Alegre: Bookman, 2001.

\section{NOTA - Endereço do autor}

Universidade Federal do Rio de Janeiro

Fac. de Adm. e Ciências Contábeis

Departamento de Ciências Contábeis
Av. Pauster, 250 - Campus da Praia Vermelha

Rio de Janeiro - RJ

22.290-240 